\title{
Prevalence of Th17 and Treg cells in gastric cancer patients and its correlation with clinical parameters
}

\author{
QIAOXIA LI ${ }^{*}$, QINGJING LI $^{1 *}$, JINXIA CHEN $^{1}$, YU LIU $^{2}$, XUEFENG ZHAO ${ }^{2}$, BIBO TAN $^{2}$, \\ JUN AI $^{1}$, ZHIPING ZHANG ${ }^{1}$, JINGJING SONG ${ }^{1}$ and BAOEN SHAN ${ }^{1}$ \\ ${ }^{1}$ Research Center and ${ }^{2}$ Department of Surgery, The Fourth Hospital of Hebei Medical University, \\ Shijiazhuang, Hebei 050011, P.R. China
}

Received March 26, 2013; Accepted May 30, 2013

DOI: $10.3892 /$ or.2013.2570

\begin{abstract}
Th17 cells and $\mathrm{CD} 4^{+} \mathrm{CD} 25^{+}$regulatory T (Treg) cells have been reported to share reciprocal developmental pathways but exhibit opposite effects, and the balance between them controls inflammation and autoimmune diseases. However, information regarding Th17/Treg cells in cancer-bearing hosts is still limited. In the present study, we investigated the distribution of Th17 cells in relation to Treg cells in gastric cancer patients, and evaluated how the imbalance in Th17/Treg cells in gastric cancer correlates with clinical and pathological parameters. We observed that the accumulation of Th17 and Treg cells in the tumor microenvironment was gradually increased according to disease progression, leading to an imbalance in Th17/Treg cells in gastric cancer patients. TGF- $\beta$ and interleukin (IL)-6 present in the gastric cancer microenvironment promoted the differentiation and expansion of Th17 cells, and increased numbers of Th17 cells promoted tumor progression through promotion of inflammation by secretion of IL-17. Treg cells promoted tumor progression by helping cancer cells escape from host immunosurveillance by secreting TGF- $\beta$, and a high level of TGF- $\beta$ in the tumor microenvironment promoted differentiation and expansion of Treg cells. In conclusion, the imbalance in Th17/Treg cells was involved in the development and progression of gastric cancer. A better understanding of the nature, regulation, and function of Th17 and Treg cells in tumor immunity may aid in the development of novel and effective immunotherapy for gastric cancer.
\end{abstract}

\section{Introduction}

Gastric cancer is one of the most common malignant diseases and contributes to a significant number of cancer-related

Correspondence to: Professor Baoen Shan, Research Center, The Fourth Hospital of Hebei Medical University, Jiankang Road 12, Shijiazhuang, Hebei 050011, P.R. China

E-mail: hbydsysbe@yahoo.com.cn

*Contributed equally

Key words: gastric cancer, Th17, regulatory $\mathrm{T}$ cells, TGF- $\beta$, interleukin-6, interleukin-17 deaths throughout the world. The precise pathogenesis of gastric cancer remains unclear, yet it has been correlated to many factors such as eating habits, environmental factors, hereditary predisposition, chronic gastritis, gastric polyps, gastric mucosa obform hyperplasy and Helicobacter pylori infection. Owing to the complicated pathogenesis, there are no specific strategies for dealing with gastric cancer. Although efforts have been made to introduce combination treatment strategies such as surgery combined with chemotherapy or chemoradiotherapy, the control of advanced gastric cancer remains extrememly difficult. Exploring new effective ways to cure gastric cancer has become an imminent issue to be solved. It has been shown that the grade of tumor-infiltrating $\mathrm{T}$ lymphocytes is correlated with a favorable outcome in cancer patients. Therefore, it is important to understand the mechanisms of immunoregulation in gastric cancer, in order to develop novel treatment strategies or to improve the efficacy of standard therapy (1).

Recently, Th17 and regulatory $\mathrm{T}$ (Treg) cells have been defined as two distinct $\mathrm{CD}^{+}{ }^{+} \mathrm{T}$ subsets from Th1 and Th2 cells, on the basis of their pattern of cytokine production and functions (2). Th17 cells are characterized as interleukin (IL)-17-producing $\mathrm{CD}^{+} \mathrm{T}$ cells which also produce IL-21, IL-22 and IL-26 $(3,4)$. Retinoid orphan nuclear receptor (RORc), which encodes the human ortholog of mouse ROR $\gamma \mathrm{t}$, is a specific transcription factor for Th17-cell lineage differentiation $(5,6)$. TGF- $\beta$, IL-6, IL-23 and IL-1 $\beta$ have been reported to collectively mediate human Th17 cell differentiation in vitro (7-9). Despite the important role of Th17 cells in host protection against infectious pathogens and in the pathogenesis of various inflammatory and autoimmune diseases, their prevalence and function in human cancer is still under investigation (10-12). Although several studies have shown the presence of Th17 cells in several types of human cancers, the mechanism of accumulation of Th17 cells or their generation and functional role in the tumor microenvironment remain largely unknown.

Treg cells, which are characterized by expression of Foxp3 in the nucleus, are functionally immunosuppressive subsets of $\mathrm{T}$ cells. They play important roles in maintaining tolerance to self components by contact-dependent suppression or by the release of anti-inflammatory cytokines, IL-10 and TGF- $\beta$. The number or functional abnormalities in Treg cells may lead 
to autoimmune disease or tumor development. Accumulating evidence suggests that increased number of Treg cells in tumor infiltrating lymphocytes (TILs) or peripheral blood mononuclear cells (PBMCs) is one of the reasons for impaired antitumor immunity in cancer-bearing hosts (13). In addition, the high number of Treg cells in several human tumors was reported to be correlated with poor prognosis and decreased survival $(14,15)$.

Although Th17 and Treg cells play different roles in the pathogenesis of diseases, reciprocal developmental pathways for their generation have been demonstrated. Naïve $T$ cells exposed to TGF- $\beta$ upregulate Foxp 3 and become induced Treg cells; however, when cultured with TGF- $\beta$ and IL-6, naïve $\mathrm{T}$ cells generate Th17 cells with pathogenic activities (16). It has been shown that the balance between Treg and Th17 cells is a key factor that regulates helper T-cell function in autoimmune disease and graft versus host disease (GVHD). However, there is limited information regarding the balance between Treg and Th17 cells in cancer patients. To evaluate whether this balance is disrupted in gastric cancer patients, and assess the possible role of Th17/Treg in the pathogenesis and progression of gastric cancer, we investigated the distribution of Th17 cells in relation to Treg cells in gastric cancer patients, and evaluated how the imbalance in Th17/Treg cells correlates with clinical and pathological parameters.

\section{Materials and methods}

Patients. Peripheral blood was collected from 45 patients with gastric cancer and 20 healthy volunteers. Lymph nodes and tumor tissues of the stomach were collected during surgery. None of the patients received radiotherapy, chemotherapy, or other medical interventions before the study. The present study was approved by the Ethics Committee of The Fourth Hospital of Hebei Medical University and written informed consent was obtained from all individuals.

Cell preparations. PBMCs were isolated by standard Ficoll-Hypaque density centrifugation of heparinized peripheral blood from the studied subjects.

Flow cytometric analysis of Th17. To analyze the prevalence of Th17 cells, IL-17-producing CD4+ lymphocytes were detected. PBMCs $\left(2 \times 10^{6}\right)$ were incubated in the presence of $50 \mathrm{ng} / \mathrm{ml}$ PMA, $1 \mu \mathrm{g} / \mathrm{ml}$ ionomycin and $10 \mu \mathrm{g} / \mathrm{ml}$ brefeldin A (all from Sigma-Aldrich, St. Louis, MO, USA) for $4 \mathrm{~h}$ at $37^{\circ} \mathrm{C}$. The cells were stained with FITC anti-human CD4 at $4^{\circ} \mathrm{C}$ for $30 \mathrm{~min}$. After the surface staining, the cells were stained with phycoerythrin (PE) anti-human IL-17A for Th17 detection after fixation and permeabilization according to the manufacturer's directions. Isotype-matched antibodies were used as controls. All of the Abs and reagents were purchased from eBioscience (San Diego, CA, USA). The number of IL- $17^{+}$cells on the gating of $\mathrm{CD}^{+}{ }^{+}$cells was evaluated, and the frequency of Th17 cells was expressed as a percentage of the total $\mathrm{CD} 4^{+}$cells.

Flow cytometric analysis of Treg cells. $\mathrm{CD} 4^{+} \mathrm{CD} 25^{+} \mathrm{FoxP} 3^{+}$ cells as Treg cells were measured using a human regulatory T-cell staining kit (eBioscience) according to the manufacturer's protocol. Briefly, the single-cell suspension was incubated
Table I. Primers for PCR.

\begin{tabular}{|c|c|c|}
\hline Gene & Sense primer & Antisense primer \\
\hline RORc & 5'-gcaacagcagcaacaggaa-3' & 5'-ccaaggtgtaggtgagggtat-3' \\
\hline IL-17 & 5'-gccatagtgaaggcaggaat-3' & 5'-gtgaggtggatcggttgtag-3' \\
\hline IL-23 & $5^{\prime}$-ctccetgatagccetgtgg-3' & 5'-tgaagcggagaaggagacg-3' \\
\hline IL-21 & $5^{\prime}$-gattagaatgcgtcaactt-3' & 5'-cctttcattgtttcctgta-3' \\
\hline IL-22 & 5'-aagaagtgctgttccetc-3' & 5'-catgtgcttagcctgttg-3' \\
\hline FoxP3 & 5'-gctggtgctggagaaggag-3' & 5'-cggatgatgccacagatgaa-3' \\
\hline IL-10 & 5'-tgagaaccaagacccagac-3' & 5'-cattcttcacctgctccac-3' \\
\hline TGF- $\beta$ & 5'-cccacaacgaaatctatgaca-3' & 5'-gctgaggtatcgccaggaat-3' \\
\hline IL-1 $\beta$ & 5'-acgaatctccgaccacca-3' & $5^{\prime}$-gcagggaaccagcatctt-3' \\
\hline IL-6 & 5'-atcatcactggtcttttggag-3' & $5^{\prime}$-ctggcttgttcctcactactc-3' \\
\hline$\beta$-actin & 5'-taagaccttcaacaccccag-3' & $5^{\prime}$-gccatctattgctcgaagtc-3' \\
\hline
\end{tabular}

RORc, retinoid orphan nuclear receptor; IL, interleukin.

with a cocktail of anti-CD4-FITC monoclonal antibody and anti-CD25-APC monoclonal antibody for $30 \mathrm{~min}$ at $4^{\circ} \mathrm{C}$. After fixation/permeabilization, the cells were blocked by normal rat serum and stained using anti-FoxP3-PE monoclonal antibody or PE-conjugated rat $\mathrm{IgG} 2 \mathrm{a}$ used as the isotype control for 45 min at $4^{\circ} \mathrm{C}$. The number of FoxP $3^{+}$cells on the gating of $\mathrm{CD} 4^{+}$cells was evaluated and the frequency of Th17 cells was expressed as a percentage of the total $\mathrm{CD} 4^{+}$cells.

Immunohistochemical staining. Paraffin-embedded samples were cut into $4-\mu \mathrm{m}$ sections, which were then processed for double staining immunohistochemistry. Briefly, the deparaffined and hydrated sections were depleted of endogenous peroxide activity by adding methanolic $\mathrm{H}_{2} \mathrm{O}_{2}$ for $20 \mathrm{~min}$. After blocking the samples with normal goat serum for 45 min, each section was stained with mouse anti-human CD4 antibody (Santa Cruz Biotechnology, Santa Cruz, CA, USA) at $4^{\circ} \mathrm{C}$ overnight. The samples were incubated with biotinylated goat anti-mouse $\operatorname{IgG}$ at $37^{\circ} \mathrm{C}$ for $30 \mathrm{~min}$, and then incubated with streptavidin-horseradish peroxidase complex for $30 \mathrm{~min}$ followed by incubation with 3,3'-diaminobenzidine. Subsequently, the sections were incubated with rabbit anti-human IL-17 antibody (Proteintech, Chicago, IL, USA) or rabbit anti-human Foxp3 antibody (Santa Cruz Biotechnology), respectively, followed by alkaline phosphatase anti-rabbit IgG, and then the sections were stained with alkaline phosphatase red. The sections were counterstained with hematoxylin.

Quantitative real-time $R T$-PCR. Tumor samples were snap-frozen in liquid nitrogen. Total RNA was extracted using TRIzol reagent (Invitrogen, Carlsbad, CA, USA). Complementary DNA was synthesized from total RNA $(0.5 \mu \mathrm{g})$ using the ReverAid ${ }^{\mathrm{TM}}$ First Strand cDNA Synthesis kit (Takara Biotechnology, Dalian, China). Subsequently, quantitative real-time PCR was performed in an ABI PRISM 7500 Cycler (Applied Biosystems, Warrington, UK) using the SYBR Premix Ex Taq ${ }^{\mathrm{TM}}$ II kit (Takara Biotechnology) for 40 cycles $\left(95^{\circ} \mathrm{C}\right.$ for $5 \mathrm{sec}, 60^{\circ} \mathrm{C}$ for $31 \mathrm{sec}$ ) after an initial 30 -sec incubation at $95^{\circ} \mathrm{C}$. The expression levels of RORc, IL-17, IL-23, IL-21, IL-22, TGF- $\beta$, IL-1 $\beta$, IL-6, Foxp3 and IL-10 were determined 
A

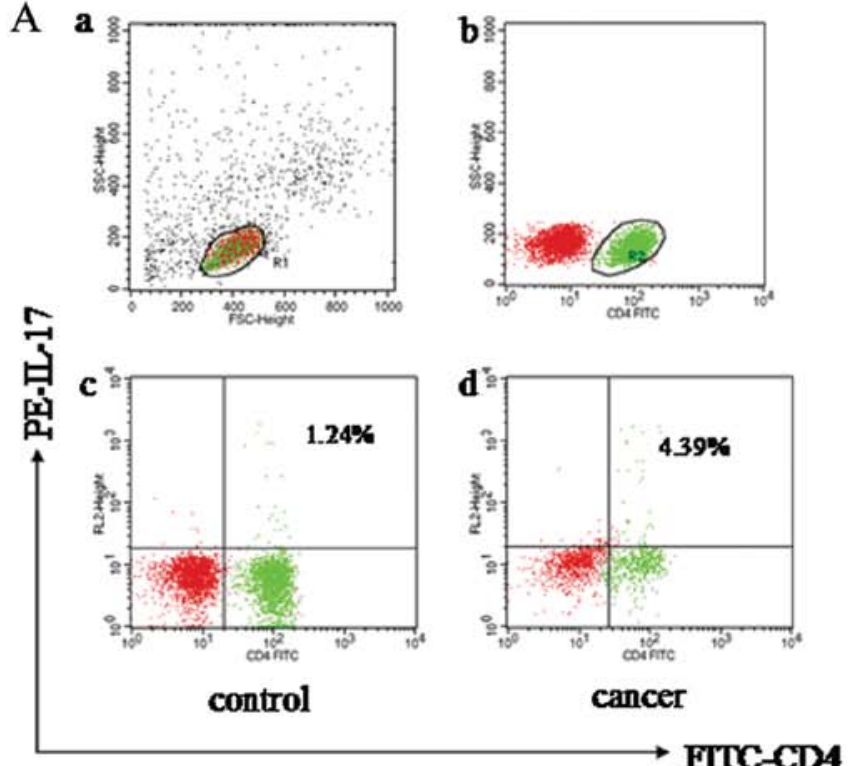

B a
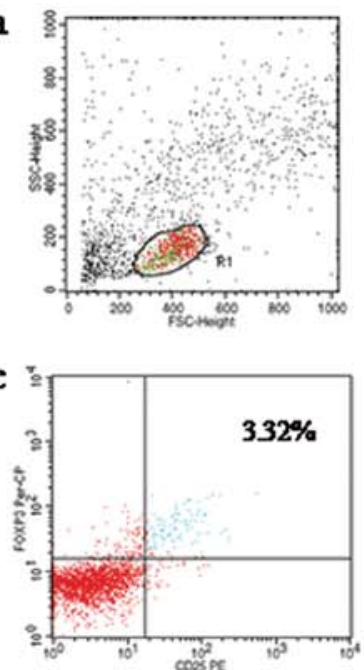

control
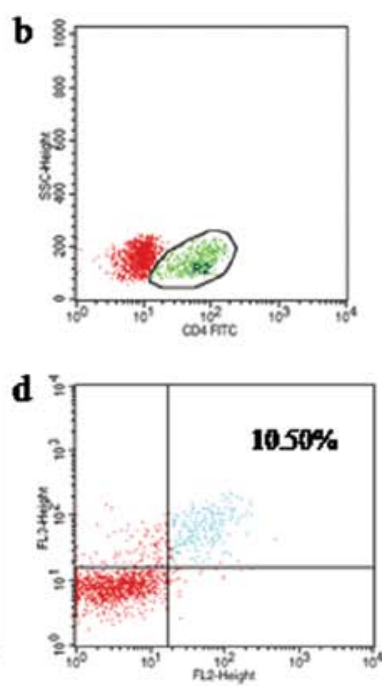

cancer
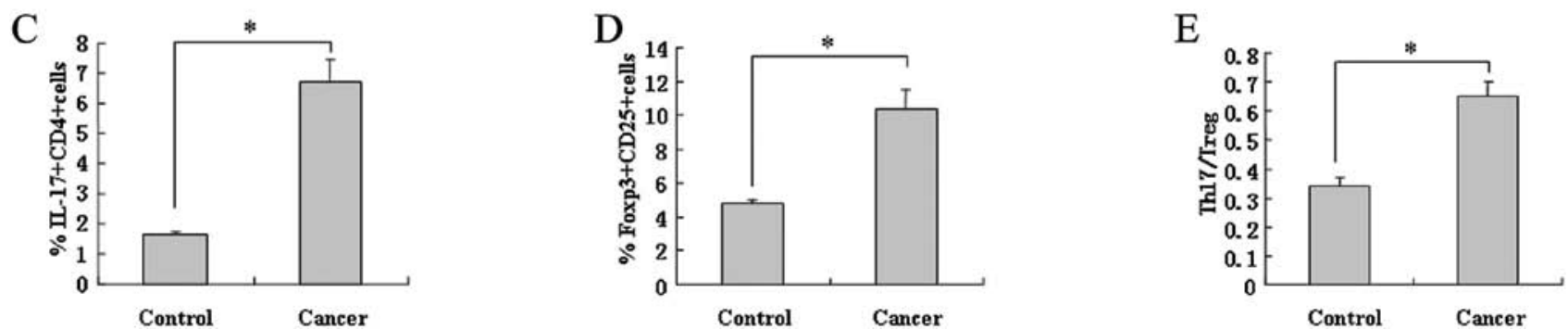

Figure 1. Prevalence of Th17 and regulatory T (Treg) cells in gastric cancer patients. For Th17 cell analysis, peripheral blood mononuclear cells (PBMCs) from all subjects were stimulated with PMA, ionomycin, and brefeldin A for $4 \mathrm{~h}$, and then stained with labeled antibodies. As for Treg cells, PBMCs from all subjects were stained with labeled antibodies. (A) The frequency of Th17 cells in controls and gastric cancer patients. (a) Lymphocytes were gated by flow cytometry. (b) $\mathrm{CD}^{+} \mathrm{T}$ subsets were gated by flow cytometry. (c and d) The proportion of Th17 cells to CD4 ${ }^{+}$subsets from representative control and gastric cancer patient. The percentage of positive cells is shown in each panel. (B) The frequency of Treg cells in controls and gastric cancer patients. (a) Lymphocytes were gated by flow cytometry. (b) $\mathrm{CD}^{+} \mathrm{T}$ subsets were gated by flow cytometry. (c and d) The proportion of Foxp3 and CD25 double staining cells to CD4 ${ }^{+}$ subsets from representative control and gastric cancer patient. The percentage of positive cells is shown in each panel. (C and D) Percentage of Th17 and Treg cells in gastric cancer patients. Significantly increased percentage of Th17 and Treg cells gated on CD4 ${ }^{+}$subjects, was found in gastric cancer patients when compared to the controls $(\mathrm{P}<0.05)$. (E) The proportion of Th17/Treg in gastric cancer patients. Obviously increased proportion of Th17/Treg was found in gastric cancer patients when compared to the controls $(\mathrm{P}<0.05)$.

from the cycle threshold values normalized to $\beta$-actin using the relative standard curve method. Primers used in the study are shown in Table I.

Statistical analysis. Data analysis was performed using SPSS 13.0. Values are expressed as means \pm SD. The Student's t-test and ANOVA analysis were used to compare the significance of differences between experimental groups. Correlations were evaluated using linear correlation analysis. The adjusted partial regression coefficient was determined using multiple linear regression. P-values $<0.05$ were considered statistically significant.

\section{Results}

Increased frequency of circulating Th17 in gastric cancer patients. PBMCs in patients with gastric cancer and in healthy donors were examined for the frequency of Th17 cells. The population of Th17 cells as a percentage of total $\mathrm{CD} 4^{+}$cells was evaluated by flow cytometric analysis. Representative dotplots are shown in Fig. 1A. Summarized data from all individuals indicated that the percentage of Th17 cells was significantly increased in patients with gastric cancer when compared to healthy donors (Fig. 1C).

We next sought to determine whether this Th17 skewing was associated with clinicopathologic status including gender, age, TNM stage, differentiation, metastatic lymph nodes, tumor factors, invasive depth, blood vessel invasion, intravascular cancer embolus and gastric cancer-related tumor antigens in gastric cancer patients. As shown in Table II, specifically, the frequency of Th17 cells was positively correlated with TNM stage and lymph node metastases. There was no association between Th17 frequency and other studied factors.

Increased frequency of circulating Treg cells in gastric cancer patients. To analyze the prevalence of Treg, $\mathrm{CD} 4{ }^{+} \mathrm{CD} 25^{+} \mathrm{FoxP} 3{ }^{+}$cells were examined by flow cytometry and expressed as a percentage of the total $\mathrm{CD} 4^{+}$cells. Representative dotplots are shown in Fig. 1B. Summarized data from all individuals showed that the frequency of Treg cells in PBMCs of gastric cancer patients was significantly higher than that in healthy donors (Fig. 1D). The association 
Table II. Association between Th17, Treg cells or Th17/Treg in peripheral blood and clinicopathologic factors of gastric cancer patients.

\begin{tabular}{|c|c|c|c|c|c|}
\hline \multirow[b]{2}{*}{ Clinical characteristic } & \multirow[b]{2}{*}{ Evaluation } & \multirow[b]{2}{*}{$\mathrm{N}=45$} & \multicolumn{3}{|c|}{ P-value } \\
\hline & & & Th17 & Treg & Th17/Treg \\
\hline Gender & & & 0.754 & 0.674 & 0.917 \\
\hline Male & 0 & 36 & & & \\
\hline Female & 1 & 9 & & & \\
\hline Age, years & & & 0.963 & 0.884 & 0.890 \\
\hline$<60$ & 0 & 24 & & & \\
\hline$\geq 60$ & 1 & 21 & & & \\
\hline TNM stage & & & $0.002^{\mathrm{a}}$ & $0.034^{\mathrm{a}}$ & 0.110 \\
\hline I & 1 & 15 & & & \\
\hline II & 2 & 9 & & & \\
\hline III & 3 & 9 & & & \\
\hline IV & 4 & 12 & & & \\
\hline Differentiation & & & 0.176 & $0.015^{\mathrm{a}}$ & 0.165 \\
\hline Well & 0 & 14 & & & \\
\hline Poor & 1 & 31 & & & \\
\hline Metastatic lymph node & & & $0.017^{\mathrm{a}}$ & 0.042 & $0.036^{\mathrm{a}}$ \\
\hline Yes & 1 & 18 & & & \\
\hline No & 0 & 27 & & & \\
\hline Size of tumor $(\mathrm{cm})$ & & & 0.262 & 0.279 & 0.476 \\
\hline$<4$ & 0 & 19 & & & \\
\hline$\geq 4$ & 1 & 26 & & & \\
\hline Invasive depth (mm) & & & 0.507 & 0.572 & 0.291 \\
\hline$<15$ & 0 & 17 & & & \\
\hline$\geq 15$ & 1 & 28 & & & \\
\hline Blood vessel invasion & & & 0.077 & 0.134 & 0.237 \\
\hline Yes & 1 & 11 & & & \\
\hline No & 0 & 34 & & & \\
\hline Intravascular cancer embolus & & & 0.508 & 0.519 & 0.623 \\
\hline Yes & 1 & 9 & & & \\
\hline No & 0 & 36 & & & \\
\hline \multicolumn{6}{|c|}{ Gastric cancer-related tumor antigens } \\
\hline CA50 (0.21-10 IU/ml) & & & 0.903 & 0.972 & 0.431 \\
\hline$<10$ & 0 & 37 & & & \\
\hline$\geq 10$ & 1 & 8 & & & \\
\hline CEA $(0-5 \mathrm{ng} / \mathrm{ml})$ & & & 0.321 & 0.465 & 0.936 \\
\hline$<5$ & 0 & 40 & & & \\
\hline$\geq 5$ & 1 & 5 & & & \\
\hline CA199 (0-27 U/ml) & & & 0.570 & 0.917 & 0.274 \\
\hline$<27$ & 0 & 29 & & & \\
\hline$\geq 27$ & 1 & 6 & & & \\
\hline CA724 (0-6.9 U/ml) & & & 0.309 & 0.274 & 0.268 \\
\hline$<6.9$ & 0 & 31 & & & \\
\hline$\geq 6.9$ & 1 & 15 & & & \\
\hline
\end{tabular}

Multiple regression analysis, ${ }^{a} \mathrm{P}<0.05$ compared with the control group. Treg, regulatory T cells.

between expression of Treg and clinical/pathologic parameters showed that the frequency of Treg cells was positively correlated with TNM stage and tumor differentiation, and there was no association between the frequency of Treg and other studied factors (Table II).

Increased proportion of Th17/Treg cells in gastric cancer patients. We also observed the proportion of Th17/Treg in gastric cancer patients. As shown in Fig. 1E, the proportion of Th17/Treg cells was significantly increased in gastric cancer patients when compared to healthy donors. In addition, compared with the gastric cancer patients without lymph node metastasis, a significantly increased ratio of Th17/Treg was found in patients with lymph node metastasis. There was no statistical correlation between the Th17/Treg ratio and other clinical/pathologic parameters (Table II). 

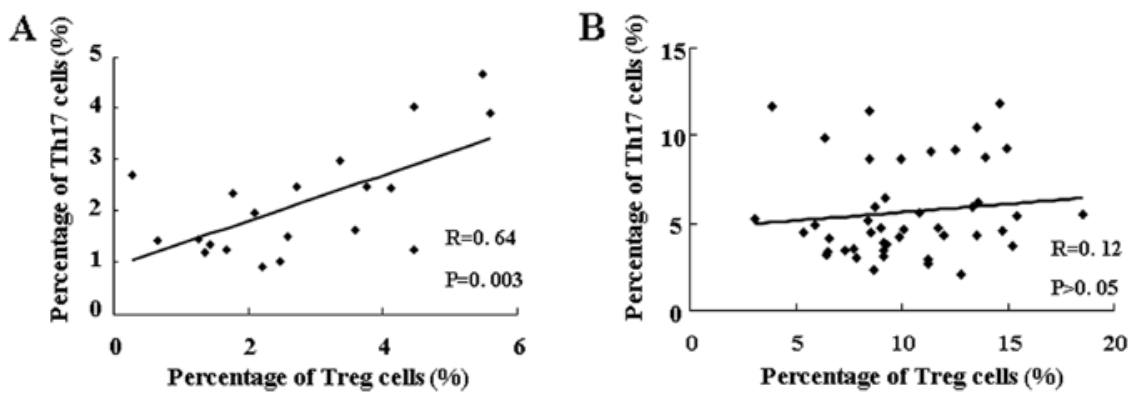

Figure 2. Correlation between Th17 and regulatory T (Treg) cells in gastric cancer patients. (A) A positive correlation between the frequency of Th17 and Treg cells was found in the healthy controls $(\mathrm{R}=0.64, \mathrm{P}=0.003)$. (B) No statistically significant correlation between Th17 and Treg cells in gastric cancer patients was found.

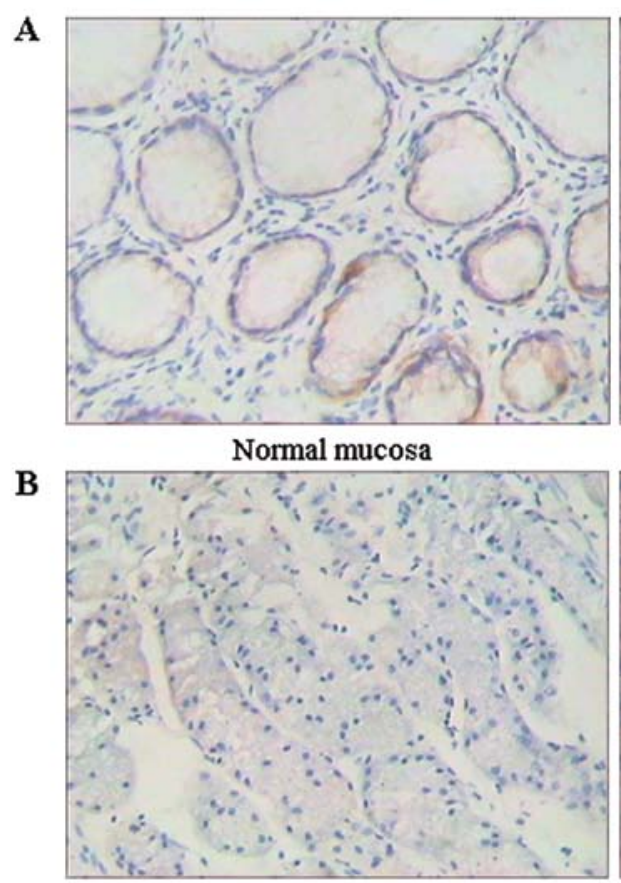

Normal mucosa

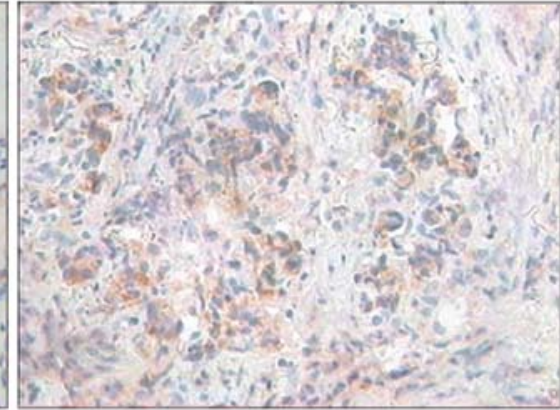

Gastric cancer

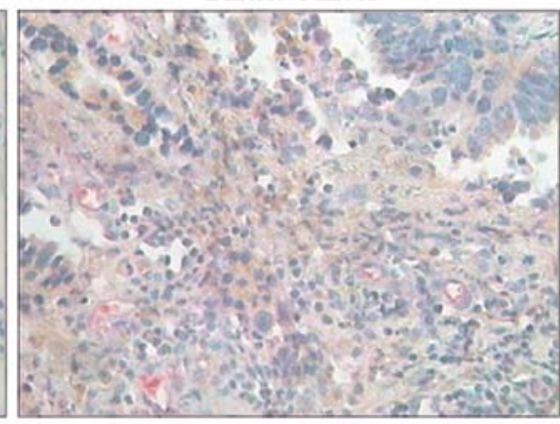

Gastric cancer

Figure 3. Immunohistochemical staining for CD4/interleukin (IL)-17 or CD4/Foxp3 in gastric cancer. Magnification, x400. (A) Representative immunostaining for CD4/IL-17 is shown for normal gastric mucosa and gastric cancer. (B) Representative immunostaining for CD4/Foxp3 is shown for normal gastric mucosa and gastric cancer. Summarized data indicated that the frequency of CD $4^{+} \mathrm{IL}-17^{+}$or $\mathrm{CD} 4^{+}$FoxP $3^{+}$cells was frequently observed in gastric cancer.

Correlation between Th17 and Treg cells. Next, we evaluated the relationship between Th17 and Treg cells in gastric cancer patients and in healthy donors. As shown in Fig. 2, the frequencies of Th17 and Treg cells were positively correlated in the healthy donors, but not correlated in the gastric cancer patients.

Distribution of Th17 and Treg cells in gastric cancer tissue. To further evaluate the frequency of Th17 and Treg cells in gastric cancer tissue, double staining immunohistochemistry (CD4 and IL-17 for Th17, or CD4 and Foxp3 for Treg) was performed. Notably, representative data revealed that $\mathrm{CD} 4^{+} \mathrm{IL}-17^{+}$or $\mathrm{CD} 4{ }^{+} \mathrm{Fox} 3^{+}$cells were frequently observed in gastric cancer in comparison to the controls (Fig. 3).

mRNA expression of RORc, IL-17, IL-23, IL-21, IL-22, TGF- $\beta$, $I L-1 \beta, I L-6$, Foxp3 and IL-10 in gastric cancer tissue. To further analyze the mechanism of Th17 and Treg accumulation in gastric cancer tissue or the relationship between the immune-imbalance of Th17/Treg and their differentiation or function in gastric cancer tissues, we also examined the mRNA expression levels of RORc, IL-17, IL-23, IL-21, IL-22, TGF- $\beta$, IL-1 $\beta$, IL-6, Foxp3 and IL-10 in gastric cancer tissue by real-time RT-PCR. As shown in Fig. 4, mRNA expression levels of RORc, IL-17, IL-21, TGF- $\beta$, IL-6, Foxp3 and IL-10 in gastric cancer were significantly increased in comparison to the controls. The correlation between RORc and cytokines showed that mRNA expression of RORc did correlate with mRNA expression of IL-17, IL-6, TGF- $\beta$ and IL-23, but did not correlate with mRNA expression of IL-21, IL-22 and IL-1 $\beta$ (Fig. 5). The correlation between Foxp3 and TGF- $\beta$ or IL-10 showed that mRNA expression of Foxp3 did correlate with mRNA expression of TGF- $\beta$, but did not correlate with mRNA expression of IL-10 (Fig. 6). 


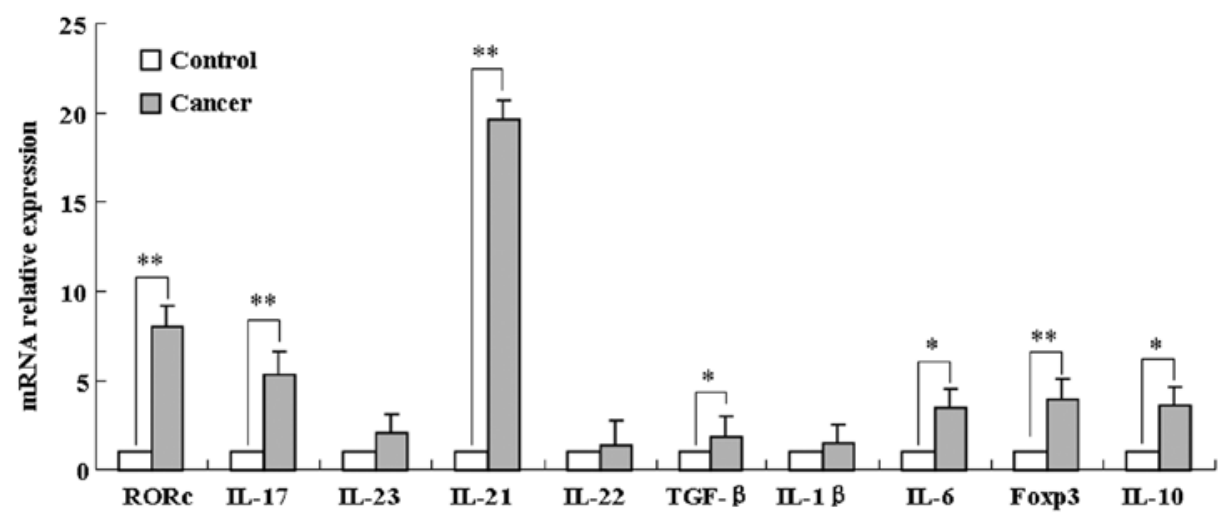

Figure 4. mRNA expression of cytokines and transcription factors in gastric cancer. Total RNA was extracted from gastric cancer and control tissues. The mRNA relative expression of indicated cytokines and specific transcription factors was analyzed by quantitative RT-PCR using the $\Delta \Delta C \mathrm{Ct}$ method with $\beta$-actin mRNA as an internal control. Data are expressed as mean $\pm \mathrm{SD} .{ }^{*} \mathrm{P}<0.05,{ }^{* *} \mathrm{P}<0.01$ vs. control.
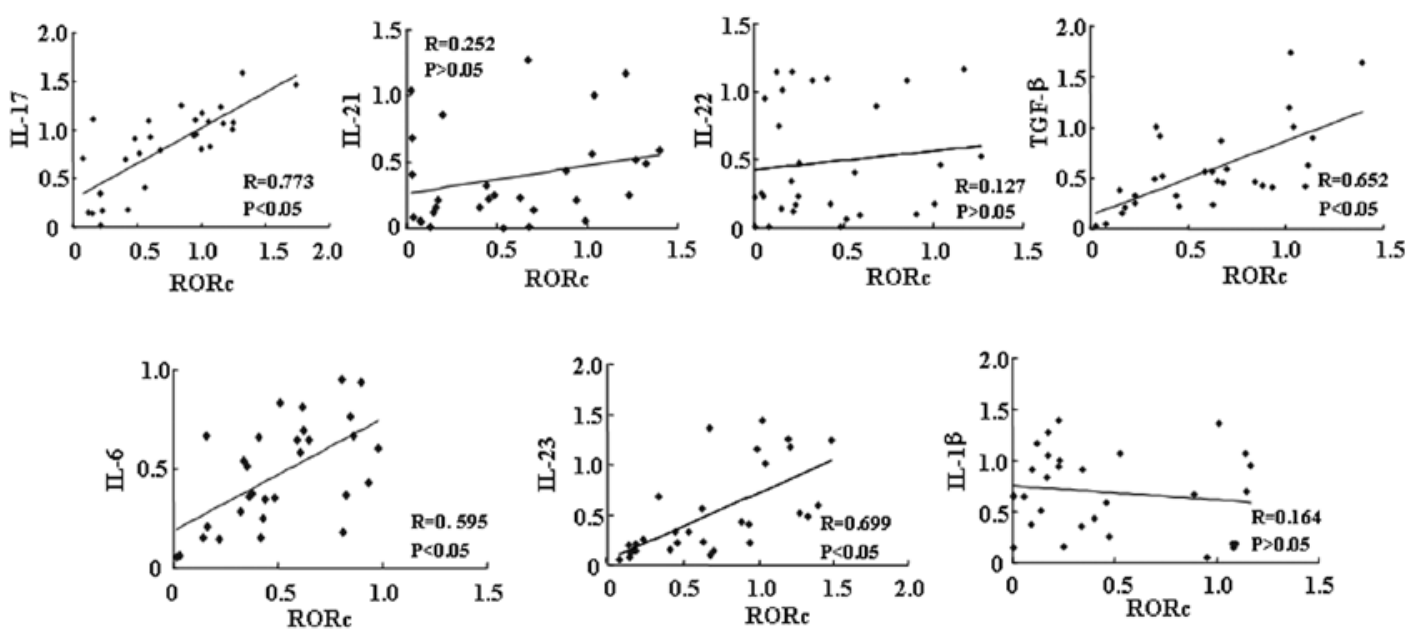

Figure 5. A linear correlation dependability analysis of retinoid orphan nuclear receptor (RORc) mRNA expression and interleukin (IL)-17, IL-21, IL-22, IL-6, IL-23 and IL-1 $\beta$ mRNA expression in gastric cancer. The mRNA expression of RORc was positively correlated with the mRNA expression of IL-17, IL-6, TGF- $\beta$ and IL-23, but did not correlate with mRNA expression of IL-21, IL-22 and IL-1 $\beta$.
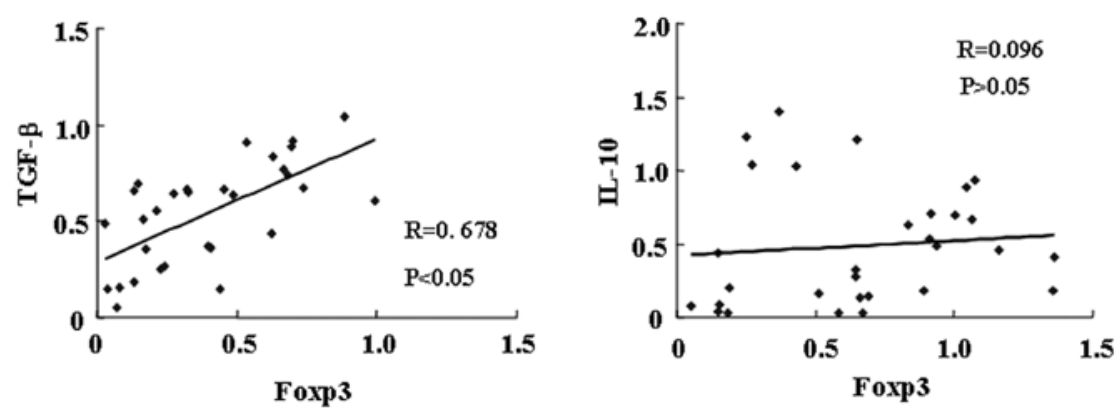

Figure 6. A linear correlation dependability analysis of Foxp3 mRNA expression and TGF- $\beta$ and interleukin (IL)-10 mRNA expression in gastric cancer. The mRNA expression of Foxp3 was positively correlated with mRNA expression of TGF- $\beta$, but did not correlate with mRNA expression of IL-10.

\section{Discussion}

Th17 and Treg cells are two newly identified important subsets of T helper cells. The Th17/Treg balance controls autoimmunity and inflammation and has been found to play an important role in the pathogenesis of tumor disease. To assess whether this balance is disturbed in gastric cancer patients, we determined the distribution of Th17 and Treg cells in gastric cancer patients, and evaluated how the imbalance of Th17/Treg cells correlates with clinical and pathological parameters.

There have been several reports describing Th17 cells in both murine and human tumors, but the nature and role of Th17 cells in cancer immunity remains elusive. Previous investigations demonstrated that the levels of Th17 cells were significantly increased in peripheral blood, malignant ascites fluid and tumor tissues in human ovarian, renal and 
pancreatic malignancies $(10,11,17,18)$. In the present study, we reconfirmed an increased number of Th17 cells in the PBMCs of patients with gastric cancer. Moreover, an increased population of Th17 cells was associated with TNM stage and lymph node metastases. Compared with patients with early stage disease, patients with advanced disease showed a significantly higher percentage of Th17 cells. Compared with patients without lymph node metastases, patients with lymph node metastases exhibited a significantly higher percentage of Th17 cells. These results are consistent with the findings of Zhang et al (9), which indicated that Th17 cells may contribute to the pathogenesis of gastric cancer.

Zhang et al also demonstrated that the levels of Th17 and Treg cells were higher in hepatocellular carcinoma than in the corresponding non-tumor tissues. Our immunohistochemical staining results showed that CD4/IL-17 double stained lymphocytes were more frequently observed in gastric cancer tissues than in their corresponding non-tumor tissues, which was consistent with our flow cytometric results that the frequency of Th17 cells was increased in PBMCs.

Since their discovery, Treg cells have gained much attention in tumor immunity, due to their strong immune suppressive activity on $\mathrm{T}$ cell responses. Accumulating evidence demonstrates that the levels of Foxp $3^{+}$Treg cells are increased in cancer patients, and the high number of Treg cells is associated with poor survival $(14,15,19-22)$. In addition, research regarding Treg cells in ovarian and prostate cancer has demonstrated that Treg cells exist in a markedly higher proportion in PBMCs, and that a significant difference in the prevalence of Treg cells between the early and advanced disease stages was found $(11,23)$. Consistently, our data showed that the frequencies of Treg cells in PBMCs were prominently increased in patients with gastric cancer. Moreover, the increased number of Treg cells was associated with TNM stage and the degree of tumor differentiation. Lymphocyte migration is modulated by chemokine receptor interaction. Previous studies have reported that the majority of tumor-associated Treg cells express lymphoid homing receptor CD62L, CCR4 and CCR6, which induce a gradual increase in Treg cells in tumors during disease progression $(23,24)$. This notion was supported by our study that the percentage of Treg cells was obviously increased in gastric cancer tissue. In addition, we also found that the frequency of Treg cells was positively correlated with the degree of tumor differentiation. These results suggest that suppression of immunity by Treg cells may be an impediment to gastric cancer therapy.

Tumor progression has been considered to be the result of an interaction between different cell types. According to the reciprocal differentiation pathways of Th17 and Treg cells and the regulatory action, Th17/Treg subsets may be involved in immunomodulation, similar to the paradigm of Th1/Th2 subsets, and the imbalance in Th17/Treg cells may lead to tumor progression. This notion was supported by Zhang's et al results (9) and our finding that the proportion of Th17/Treg was significantly increased in gastric cancer patients when compared to healthy donors. In addition, the frequencies of Th17 and Treg cells were well correlated in the healthy donors, but not in the gastric cancer patients, which may reflect that an immune balance exists in healthy individuals but has been disrupted in gastric cancer patients. Moreover, compared with patients without lymph node metastases, an obviously increased ratio of Th17/Treg cells was found in gastric cancer patients with lymph node metastases. These data suggest that the immune imbalance between Th17 and Treg cells may potentially play an important role in the development and progression of gastric cancer.

To further analyze the mechanism of Th17 and Treg accumulation in gastric cancer tissue or the relationship between the immune-imbalance of Th17/Treg and their differentiation or function in gastric cancer tissues, we examined the mRNA expression levels of Th17- and Treg-related cytokines. Our results demonstrated that the mRNA expression level of Th17specific transcript factor RORc was significantly elevated in gastric cancer tissues, which was consistent with the elevation of Th17 in peripheral blood. Moreover, the mRNA expression level of RORc was positively correlated with that of IL-17, further elevated prevalence of Th17 cells was associated with higher TNM stages. We, therefore, conclude that increased expression of IL-17 in gastric cancer tissue, most likely, originates from Th17 cells, and Th17 cells may promote tumor progression by promoting inflammation through secretion of IL-17.

Recently, TGF- $\beta$, IL- $1 \beta$ and IL- 6 have been recognized as the most important cytokines for the initiation of Th17 cell differentiation, whereas IL-23, originally thought to be the master regulator, appears to be important for expansion and/or maintenance of the Th17 response (25-30). In the present study, we found that mRNA expression of both TGF- $\beta$ and IL- 6 was much higher in gastric cancer tissues than in non-cancerous adjacent tissues. Importantly, in tumor tissues, both TGF- $\beta$ and IL-6 mRNA expression levels showed a strong correlation with the RORc mRNA expression level. We also examined IL-1 $\beta$ and IL-23, but we did not find a correlation between them and RORc. These results suggest that TGF- $\beta$ and IL-6 present in the gastric cancer microenvironment may promote differentiation and expansion of Th17 cells. Our results are consistent with data from Manel et al (7) and Yang et al (31).

Foxp3 is the characteristic transcription factor for Treg cells. At the mRNA and protein levels, $\mathrm{CD} 4^{+} \mathrm{T}$ cells expressing Foxp 3 in the periphery are mainly $\mathrm{CD}^{+} \mathrm{CD} 25^{+}$Treg cells. Treg cells suppress immune responses by a contact-dependent manner or modulate the immune balance through the release of cytokines IL-10 and TGF- $\beta$. The present study showed that mRNA expression of FoxP3, IL-10 and TGF- $\beta$ was much higher in gastric cancer tissues than in non-cancerous adjacent tissues and that the high mRNA expression levels of Foxp3 and TGF- $\beta$ were associated with higher TNM stage. Our data were consistent with the results from several studies demonstrating that Treg cells are increased in blood, TDLN and cancer specimens from patients with gastric cancer $(32,33)$. Previous studies have shown that Th17 and Treg cells are synchronistically increased following tumor development, and both populations reached maximal levels in advanced tumor $(2,9,11,34,35)$. Our data further reconfirmed this finding. Therefore, the dynamic interaction between Th17 and Treg cells may be important in the development of gastric cancer.

In conclusion, the accumulation of Th17 and Treg cells in the gastric cancer tumor microenvironment was gradually increased according to disease progression, leading to an imbalance in Th17/Treg cells in gastric cancer patients. 
TGF- $\beta$ and IL- 6 present in the gastric cancer microenvironment promoted the differentiation and expansion of Th17 cells, and increased Th17 cells promoted tumor progression through promotion of inflammation by secretion of IL-17. Treg cells promoted tumor progression by helping cancer cells escape from host immunosurveillance by secreting TGF- $\beta$, and a high level of TGF- $\beta$ in the tumor microenvironment promoted differentiation and expansion of Treg cells. A better understanding of the nature, regulation, and function of Th17 and Treg cells in tumor immunity may aid in the development of novel and effective immunotherapy for gastric cancer.

\section{Acknowledgements}

The present study was supported by grants from the Natural Science Foundation of Hebei Province (no. C2011206086); Key Science and Technology Project of the Health Department of Hebei Province (no. 20110456).

\section{References}

1. Maruyama T, Kono K, Mizukami Y, Kawaguchi Y, Mimura K, Watanabe M, Izawa S and Fujii H: Distribution of Th17 cells and FoxP3(+) regulatory T cells in tumor-infiltrating lymphocytes, tumor-draining lymph nodes and peripheral blood lymphocytes in patients with gastric cancer. Cancer Sci 101: 1947-1954, 2010.

2. Zhang Y, Ma D, Zhang Y, Tian Y, Wang X, Qiao Y and Cui B: The imbalance of Th17/Treg in patients with uterine cervical cancer. Clin Chim Acta 412: 894-900, 2011.

3. Korn T, Bettelli E, Oukka M and Kuchroo VK: IL-17 and Th17 cells. Annu Rev Immunol 27: 485-517, 2009.

4. Dong C: Diversification of T-helper-cell lineages: finding the family root of IL-17-producing cells. Nat Rev Immunol 6: 329-333, 2006

5. Ivanov II, McKenzie BS, Zhou L, Tadokoro CE, Lepelley A, Lafaille JJ, Cua DJ and Littman DR: The orphan nuclear receptor ROR $\gamma \mathrm{t}$ directs the differentiation program of proinflammatory IL-17 ${ }^{+} \mathrm{T}$ helper cells. Cell 126: 1121-1133, 2006.

6. McGeachy MJ and Cua DJ: Th17 cell differentiation: the long and winding road. Immunity 28: 445-453, 2008.

7. Manel N, Unutmaz D and Littman DR: The differentiation of human $\mathrm{T}(\mathrm{H})-17$ cells requires transforming growth factor-beta and induction of the nuclear receptor ROR $\gamma \mathrm{t}$. Nat Immunol 9: 641-649, 2008

8. Volpe E, Servant N, Zollinger R, Bogiatzi SI, Hupé P, Barillot E and Soumelis V: A critical function for transforming growth factor-beta, interleukin 23 and proinflammatory cytokines in driving and modulating human $\mathrm{T}(\mathrm{H})-17$ responses. Nat Immunol 9: 650-657, 2008.

9. Zhang B, Rong G, Wei H, Zhang M, Bi J, Ma L, Xue X, Wei G, Liu X and Fang G: The prevalence of Th17 cells in patients with gastric cancer. Biochem Biophys Res Commun 374: 533-537, 2008 .

10. Sfanos KS, Bruno TC, Maris CH, Xu L, Thoburn CJ, DeMarzo AM, Meeker AK, Isaacs WB and Drake CG: Phenotypic analysis of prostate-infiltrating lymphocytes reveals TH17 and Treg skewing. Clin Cancer Res 14: 3254-3261, 2008.

11. Kryczek I, Wei S, Zou L, Altuwaijri S, Szeliga W, Kolls J, Chang A and Zou W: Cutting edge: Th17 and regulatory T cell dynamics and the regulation by IL- 2 in the tumor microenvironment. J Immunol 178: 6730-6733, 2007.

12. Su X, Ye J, Hsueh EC, Zhang Y, Hoft DF and Peng G: Tumor microenvironments direct the recruitment and expansion of human Th17 cells. J Immunol 184: 1630-1641, 2010.

13. Wang RF: Regulatory T cells and innate immune regulation in tumor immunity. Springer Semin Immunopathol 28: 17-23, 2006.

14. Nakamura T, Shima T, Saeki A, Hidaka T, Nakashima A, Takikawa $\mathrm{O}$ and Saito S: Expression of indoleamine 2,3-dioxygenase and the recruitment of Foxp3-expressing regulatory $\mathrm{T}$ cells in the development and progression of uterine cervical cancer. Cancer Sci 98: 874-881, 2007.
15. Wolf D, Wolf AM, Rumpold H, Fiegl H, Zeimet AG, Muller-Holzner E, Deibl M, Gastl G, Gunsilius E and Marth C: The expression of the regulatory $\mathrm{T}$ cell-specific forkhead box transcription factor FoxP3 is associated with poor prognosis in ovarian cancer. Clin Cancer Res 11: 8326-8331, 2005.

16. Vernal R and Garcia-Sanz JA: Th17 and Treg cells, two new lymphocyte subpopulations with a key role in the immune response against infection. Infect Disord Drug Targets 8: 207-220, 2008

17. Kryczek I, Banerjee M, Cheng P, et al: Phenotype, distribution, generation, and functional and clinical relevance of Th17 cells in the human tumor environments. Blood 114: 1141-1149, 2009.

18. Miyahara Y, Odunsi K, Chen W, Peng G, Matsuzaki J and Wang RF: Generation and regulation of human CD4 ${ }^{+}$ IL-17-producing T cells in ovarian cancer. Proc Natl Acad Sci USA 105: 15505-15510, 2008.

19. Beyer M and Schultze JL: Regulatory T cells in cancer. Blood 108: 804-811, 2006.

20. Byrne WL, Mills KH, Lederer JA and O'Sullivan GC: Targeting regulatory T cells in cancer. Cancer Res 71: 6915-6920, 2011.

21. Shen S, Liang L, Peng BG, He Q, Kuang M and Lai JM: Foxp3 ${ }^{+}$ regulatory $\mathrm{T}$ cells and the formation of portal vein tumor thrombus in patients with hepatocellular carcinoma. Can J Surg 54: 89-94, 2011.

22. Xu L, Xu W, Qiu S and Xiong S: Enrichment of CCR6 ${ }^{+}$Foxp3 $^{+}$ regulatory $\mathrm{T}$ cells in the tumor mass correlates with impaired $\mathrm{CD}^{+} \mathrm{T}$ cell function and poor prognosis of breast cancer. Clin Immunol 135: 466-475, 2010.

23. Miller AM, Lundberg K, Ozenci V, Banham AH, Hellström M, Egevad L and Pisa P: CD4 ${ }^{+} \mathrm{CD} 25^{\text {high }} \mathrm{T}$ cells are enriched in the tumor and peripheral blood of prostate cancer patients. J Immunol 177: 7398-7405, 2006.

24. Curiel TJ, Coukos G, Zou L, et al: Specific recruitment of regulatory $\mathrm{T}$ cells in ovarian carcinoma fosters immune privilege and predicts reduced survival. Nat Med 10: 942-949, 2004.

25. Acosta-Rodriguez EV, Napolitani G, Lanzavecchia A and Sallusto F: Interleukins 1beta and 6 but not transforming growth factor-beta are essential for the differentiation of interleukin 17-producing human $\mathrm{T}$ helper cells. Nat Immunol 8: 942-949, 2007.

26. Wilson NJ, Boniface K, Chan JR, et al: Development, cytokine profile and function of human interleukin 17-producing helper T cells. Nat Immunol 8: 950-957, 2007.

27. Bettelli E, Carrier Y, Gao W, Korn T, Strom TB, Oukka M, Weiner HL and Kuchroo VK: Reciprocal developmental pathways for the generation of pathogenic effector TH17 and regulatory T cells. Nature 441: 235-238, 2006.

28. Mangan PR, Harrington LE, O'Quinn DB, Helms WS Bullard DC, Elson CO, Hatton RD, Wahl SM, Schoeb TR and Weaver CT: Transforming growth factor-beta induces development of the $\mathrm{T}(\mathrm{H}) 17$ lineage. Nature 441: 231-234, 2006.

29. Veldhoen M, Hocking RJ, Atkins CJ, Locksley RM and Stockinger B: TGFbeta in the context of an inflammatory cytokine milieu supports de novo differentiation of IL-17-producing T cells. Immunity 24: 179-189, 2006.

30. Stritesky GL, Yeh N and Kaplan MH: IL-23 promotes maintenance but not commitment to the Th17 lineage. J Immunol 181: 5948-5955, 2008.

31. Yang L, Anderson DE, Baecher-Allan C, Hastings WD, Bettelli E, Oukka M, Kuchroo VK and Hafler DA: IL-21 and TGF-beta are required for differentiation of human $\mathrm{T}(\mathrm{H}) 17$ cells. Nature 454: 350-352, 2008.

32. Ichihara F, Kono K, Takahashi A, Kawaida H, Sugai H and Fujii H: Increased populations of regulatory $\mathrm{T}$ cells in peripheral blood and tumor-infiltrating lymphocytes in patient with gastric and esophageal cancers. Clin Cancer Res 9: 4404-4408, 2003.

33. Sasada T, Kimura M, Yoshida Y, Kanai M and Takabayashi A: $\mathrm{CD} 4{ }^{+} \mathrm{CD} 25^{+}$regulatory $\mathrm{T}$ cells in patients with gastrointestinal malignancies: possible involvement of regulatory $\mathrm{T}$ cells in disease progression. Cancer 98: 1089-1099, 2003.

34. Bouchliou I, Miltiades P, Nakou E, et al: Th17 and Foxp3(+) $\mathrm{T}$ regulatory cell dynamics and distribution in myelodysplastic syndromes. Clin Immunol 139: 350-359, 2011.

35. Hou F, Li Z, Ma D, Zhang W, Zhang Y, Zhang T, Kong B and Cui B: Distribution of Th17 cells and Foxp3-expressing T cells in tumor-infiltrating lymphocytes in patients with uterine cervical cancer. Clin Chim Acta 413: 1848-1854, 2012. 